\title{
X Congreso Ibérico de Agroingeniería

\section{Efectos del recubrimiento con sulfato de zinc sobre tasas de germinación y niveles de isoenzimas en semillas de algodón}

\author{
José de Souza Abreu Júnior ${ }^{1}$, Leopoldo Mario Baudet ${ }^{2}$, Cassyo de Araújo Rufino ${ }^{1}$, Jucilayne \\ Fernandes Veira ${ }^{3}$, Jesús Martín-Gil' ${ }^{4}$ Pablo Martín-Ramos ${ }^{5}$ \\ 1 Faculdade de Guanambi, membro de pesquisa do Observatório FG do Semi-Árido Nordestino. Av. \\ Senador Nilo Coelho, S/N, CEP 46430-000, Bairro São Sebastião, Guanambi, Bahia. \\ 2 Departamento de Fitotecnia da Universidade de Pelotas - UFPel, CEP 96001-970, Pelotas, RS, Brasil. \\ 3 Agência de Defesa Agropecuária da Bahia - ADAB. Avenida Adhemar de Barros, 967, Ondina, \\ Salvador - Bahia, 40.170-110, Brasil. \\ 4 Departamento de Ingeniería Agroforestal, ETSIIAA, Universidad de Valladolid, Avenida de Madrid \\ 44, 34004 Palencia, España \\ 5 Departamento de Ciencias Agrarias y del Medio Natural, EPS, Universidad de Zaragoza, Carretera de \\ Cuarte, s/n, 22071 Huesca, España.
}

Resumen: Se han estudiado los parámetros fisiológicos y enzimáticos de semillas y plántulas de algodón variedad BRS 286 tratadas con sulfato de zinc, antes y después de su almacenaje durante 4 meses. Las semillas de algodón se han recubierto con una película utilizando distintas dosis de $\mathrm{ZnSO}_{4}$ (hasta $11,6 \mathrm{~g} / \mathrm{kg}$ de semillas) en combinación con un fungicida y un insecticida en una matriz polimérica. La calidad fisiológica antes y después del almacenaje se ha analizado mediante pruebas de germinación y ensayos de primer recuento. En los tests de germinación, aunque las diferencias no han sido estadísticamente significativas, se ha observado que las dosis de 2,9 y 5,8 g de $\mathrm{ZnSO}_{4} / \mathrm{kg}$ de semillas han mejorado las tasas de germinación, superando el 90\%, mientras que dosis más altas ( 8,65 y $11,6 \mathrm{~g}$ de $\mathrm{ZnSO}_{4} / \mathrm{kg}$ de semillas) han conducido a valores inferiores al control. Las dosis más altas también han producido una reducción del vigor tras 120 días de almacenaje. Respecto a las cuatro isoenzimas cuya actividad se ha medido para evaluar la calidad de las semillas (carboxilesterasa, fosfatasa ácida, glutamato-oxalacetato transaminasa y glutamato deshidrogenasa), se han registrado diferencias para dos enzimas tras 120 días de almacenaje. Los valores más bajos de carboxilesterasa (cuyo aumento va asociado al metabolismo de lípidos y a degeneración de la membrana) y los más altos de glutamatooxalacetato transaminasa (clave en el metabolismo de las proteínas) se han obtenido para una dosis de $\mathrm{ZnSO}_{4}$ de 5,8 g de $\mathrm{ZnSO}_{4} / \mathrm{kg}$ de semillas). El estudio sugiere que la aplicación del sulfato de zinc a esta dosis, en forma de composite, mejora la viabilidad de las semillas de algodón durante su almacenaje.

Palabras clave: coating; composite; Gossypium hirsutum L.; micronutrientes; zinc

\section{Introducción}

Un requerimiento usual de la industria textil es que las materias primas para la producción de ropa sean, en gran medida, compatibles con la piel humana. Esta exigencia ha hecho aumentar mucho la demanda de algodón pluma, de la que Brasil es un exportador importante. El comienzo de la producción de algodón pluma se inicia por la elección de semillas de calidad, que garantice 


\section{CONGRESO IBÉRICO DE AGROINGENIERÍA \\ X CONGRESSO IBÉRICO DE AGROENGENHARIA \\ 3 - 6 septiembre 2019, Huesca - España}

su vigor y sostenibilidad. En este escenario es necesario el uso de técnicas de bajo costo sobre la base de que la aplicación de micronutrientes es esencial para alcanzar buenos índices de productividad y calidad.

La USDA estima que la producción de algodón 2018/19 de Brasil alcanzó un récord de 12,8 millones de fardos de 480 libras, con un aumento de 3,6 millones de fardos (39\%) respecto al año anterior. El área cosechada se estima en 1,6 millones de hectáreas, un 36\% más que el año pasado. El rendimiento se estima en un récord de 1,747 kg/ha, superando el récord anterior (2017/18) en un $2 \%$ [1].

Muchos factores son responsables de estas mejoras en el rendimiento, pero una mejor utilización del suelo ha sido considerada como un punto clave. La fertilización también es crucial $\mathrm{y}$, a este respecto, debe tenerse en cuenta que el algodón es particularmente sensible a la deficiencia de zinc. Una deficiencia de este micronutriente tiene varios efectos perjudiciales en la planta: las puntas de las raíces se agrandan y los pelos radiculares se tuercen; se produce la caída de los brotes florales; las cápsulas son pequeñas y algunas veces tienen extremos romos; las flores se caen antes de que se formen las cápsulas, etc. Todas estas anomalías contribuyen a la pérdida de rendimiento.

El zinc también actúa como activador de varias enzimas y como componente estructural de otros. Se considera esencial para la síntesis de triptófano, que, a su vez, es el precursor del ácido indol-3-acético, que aumenta el volumen celular [2].

El suelo es la principal fuente de zinc para las plantas, pero muchos factores pueden afectar a su disponibilidad y es conveniente suministrarlo en las semillas, el suelo y mediante aplicación foliar. Existen experimentos que muestran diferentes respuestas a la aplicación de micronutrientes entre cultivares y entre especies [3-13].

Si el tratamiento con zinc va dirigido a la semilla, se debe prestar especial atención no solo a su calidad, sino también a una aplicación adecuada y una correcta distribución del producto [14]. Entre los métodos de tratamiento de semillas, el revestimiento con película (método utilizado en este estudio) ha ganado popularidad en los últimos años debido a las ventajas siguientes: asegura una uniformidad superior a la que se obtiene con la aplicación de lechadas (o pastas aguadas); minimiza la dispersión de los pesticidas en el medio ambiente; cuando los protectores de plantas se aplican a la semilla con encapsulación, trabajan en un área específica; la dosis completa originalmente aplicada a la semilla queda disponible para combatir las plagas en el entorno, etc. [15].

Respecto al potencial de almacenaje de las semillas, este puede verse influenciado por muchos factores, desde la fase de producción en el campo a los procedimientos de recolección y procesamiento. Por lo tanto, garantizar las condiciones de conservación que mantienen la calidad de la semilla también debe considerarse una prioridad [16].

Otro enfoque importante para evaluar la calidad de las semillas es a través del estudio de los procesos enzimáticos y en concreto de las isoenzimas, en cuanto productos de la expresión génica: los genes que controlan su expresión se manifiestan en ciertas etapas del desarrollo y en órganos y tejidos específicos, o bajo un estímulo particular [17]. Los isoenzimas vienen siendo utilizados como marcadores en estudios de viabilidad, ya que son efectivos para conocer mejor los cambios degenerativos y la muerte de las semillas [18].

Carboxilesterasa (CES, EC 3.1.1.1) y fosfatasa ácida (AP, EC 3.1.3.2) son hidrolasas que participan en las reacciones de hidrólisis de los ésteres y que han sido puestas en relación con el proceso degenerativo de la membrana involucrando la peroxidación lipídica [19],[20,21]. Según Vieira, et al. [22], ambas esterasas se pueden usar como marcadores del proceso de deterioro de la semilla. La glutamato deshidrogenasa (GLDH, EC 1.4.1.3) actúa en la oxidación de las proteínas de almacenaje para suministrar energía a las células (ciclo de Krebs) y/o en la reducción de cetoglutarato para la síntesis de aminoácidos [23], y probablemente desempeña un papel importante en la germinación de la semilla, aportando energía al proceso, o aminoácidos para el 
desarrollo embrionario. La glutamato-oxalacetato transaminasa (GOT, EC 2.6.1.1) es responsable de la oxidación de los aminoácidos, proporciona energía al ciclo de Krebs y participa en la reducción del cetoglutarato para la síntesis de nuevos aminoácidos como fuente de energía para el embrión en desarrollo. Tiene un papel fundamental en el metabolismo de las proteínas, no solo durante la germinación, sino a lo largo del ciclo de vida de la planta [24].

Distintos trabajos han destacado el potencial de estos sistemas de isoenzimas para indicar el estado de deterioro de las semillas de especies como el algodón [25], el maíz [19], la alubia [21,26] o la soja y la cebada [27], ayudando así en la evaluación del potencial fisiológico de las semillas. La utilización del patrón de expresión de sistemas de isoenzimas específicas resulta, así, enteramente recomendable como herramienta complementaria para evaluar el potencial fisiológico de la semilla, más teniendo en cuenta el bajo coste de esta práctica.

En el presente trabajo se ha analizado el efecto del recubrimiento de semillas de algodón con diferentes dosis de $\mathrm{ZnSO}_{4}$, en combinación con un fungicida, un insecticida y un polímero, sobre los atributos fisiológicos y enzimáticos de las semillas y las plántulas antes y después del almacenaje mediante pruebas de germinación y de primer recuento de plántulas, y mediante el estudio de cuatro patrones de isoenzimas representativos, respectivamente.

\section{Material y métodos}

La parte experimental del estudio se realizó en el Laboratório Didático de Análise de Sementes (LDAS) y en las instalaciones de invernadero de la Facultad de Agronomía "Elisha Maciel" (FAEM) en la Universidade Federal de Pelotas (RS, Brasil).

La Fundação Bahia - Luís Eduardo Magalhães/BA suministró las semillas del cultivar de algodón BRS 286 (ciclo de 140-160 días y tamaño bajo a mediano). En el momento del estudio, este cultivar presentaba una tasa de germinación del $88 \%$.

Los tratamientos consistieron en la aplicación de $\mathrm{ZnSO}_{4}$ a diferentes dosis, combinado con un fungicida (Maxin-XL ${ }^{\oplus}, 2 \mathrm{~mL} \cdot \mathrm{kg}^{-1}$ de semilla), un insecticida (Cruise $350 \mathrm{FS}{ }^{\circledast}, 4 \mathrm{~mL} \cdot \mathrm{kg}^{-1} \mathrm{de}$ semilla) y un polímero (Colorseed $\mathrm{HE}^{\circledR}, 4 \mathrm{~mL} \cdot \mathrm{kg}^{-1}$ de semilla). Se utilizaron los siguientes códigos: "T0" corresponde al control de semilla no tratada; "T1" al control con recubrimiento de fungicida (F) + insecticida (I) + polímero (P); “T2" a 2,895 g de ZnSO $\cdot \mathrm{kg}^{-1}$ semilla + F + I + P; “T3” a 5,795 g de $\mathrm{ZnSO}_{4} \cdot \mathrm{kg}^{-1}$ semilla + F + I + P; “T4" a 8,65 g de $\mathrm{ZnSO}_{4} \cdot \mathrm{kg}^{-1}$ semilla + F + I + P; y “T5" a 11,585 g de $\mathrm{ZnSO}_{4} \cdot \mathrm{kg}^{-1}$ semilla $+\mathrm{F}+\mathrm{I}+\mathrm{P}$.

Las semillas se recubrieron de acuerdo con el método descrito por Nunes [28], un procedimiento manual que utiliza bolsas de polietileno. El insecticida, el fungicida, el $\mathrm{ZnSO}_{4}$ y el polímero se colocaron directamente en el fondo de la bolsa de plástico hasta una altura de aproximadamente $15 \mathrm{~cm}$. Posteriormente, se agregó $1 \mathrm{~kg}$ de semillas y la bolsa de plástico se agitó durante $3 \mathrm{~min}$. Las semillas se dejaron secar a temperatura ambiente durante $24 \mathrm{~h}$. Este procedimiento se repitió hasta obtener el número necesario de semillas para cada tratamiento.

Después del tratamiento, parte de las semillas se sometieron a una evaluación de su calidad inicial y el resto se dividió en muestras de $100 \mathrm{~g}$, que se envolvieron en un papel con un espesor de $0,125 \mathrm{~mm}$ y se almacenaron en condiciones no controladas a una temperatura promedio de $22.3{ }^{\circ} \mathrm{C}$ y a humedad relativa del $78,4 \%$ para su estudio después de 120 días (de noviembre de a marzo). Contenido de humedad de la semilla al inicio y al final del período de almacenaje.

Para la evaluación de la calidad fisiológica de las semillas, la prueba de germinación (germination test, GT) se realizó con 200 semillas por tratamiento, divididas en cuatro réplicas de 50 semillas, que se sembraron en papel "Germitest" humedecido con una cantidad de agua destilada equivalente a tres veces el peso del papel seco, y posteriormente se mantuvieron en un germinador a $25^{\circ} \mathrm{C}$. Los recuentos se realizaron cuatro y doce días después de la siembra, según lo prescrito por Brasil Mapa/ACS [29]. El primer recuento de germinación (first germination count, FGC) se realizó conjuntamente con la prueba de germinación, contando las plántulas normales 


\section{CONGRESO IBÉRICO DE AGROINGENIERÍA \\ X CONGRESSO IBÉRICO DE AGROENGENHARIA \\ 3 - 6 septiembre 2019, Huesca - España}

cuatro días después del inicio de la prueba. Los resultados se expresaron como porcentaje de plántulas normales.

Para la diferenciación de isoenzimas, las elegidas fueron carboxilesterasa (EC 3.1.1.1), fosfatasa ácida (AP, EC 3.1.3.2), glutamato-oxalacetato transaminasa (EC 2.6.1.1) y glutamato deshidrogenasa (EC 1.4.1.3). Las semillas germinaron y las plántulas, después de cuatro días, se utilizaron para la extracción. También se realizaron análisis en las semillas secas (no germinadas) antes y después del almacenaje, con fines de comparación.

Para cada tratamiento y repetición, diez semillas y plántulas se recolectaron al azar y se molieron en un mortero de porcelana con hielo. Se colocaron alícuotas de $200 \mathrm{mg}$ del extracto vegetal de cada una de las muestras en un tubo Eppendorf con una solución tampón de gel extractor (gel tampón $+0,15 \%$ de 2-mercaptoetanol) en una proporción 1:2 (p/v). La electroforesis se realizó en geles de poliacrilamida al 7\%, colocando $20 \mu \mathrm{L}$ de cada muestra en los pocillos. Los patrones enzimáticos se analizaron mediante el sistema tampón [30]. Los geles se depositaron en cubas electroforéticas verticales y se mantuvieron en una cámara fría a $4-6{ }^{\circ} \mathrm{C}$. Las migraciones electroforéticas se realizaron con una diferencia de potencial de $1.0 \mathrm{~V} \cdot \mathrm{mm}^{-1}$, hasta que la línea frontal formada por azul de bromofenol alcanzó $90 \mathrm{~mm}$ desde el punto de aplicación. Los geles de electroforesis se fijaron en una solución de agua destilada:metanol:ácido acético a 5:5:1 (v/v). Teniendo en cuenta la presencia/ausencia e intensidad de cada banda electroforética, la interpretación de los resultados se basó en el análisis visual de los geles de electroforesis [31,32].

Con respecto al análisis estadístico, se utilizó un diseño completamente aleatorio con cuatro repeticiones. Los datos se analizaron para determinar la normalidad y la homocedasticidad y posteriormente se sometieron a análisis de varianza $(\mathrm{p}<0,05)$. Con una probabilidad significativa de F, las medias se compararon mediante la prueba de Dunnett frente a T1.

\section{Resultados y discusión}

\subsection{Calidad fisiológica}

\subsubsection{Ensayo de germinación}

Los resultados de la prueba de germinación se resumen en la Tabla 1. No se encontraron diferencias significativas entre las muestras tratadas con $\mathrm{ZnSO}_{4}$ y los controles, ni antes ni después del almacenaje. Estos resultados están de acuerdo con las observaciones recogidas en la bibliografía para otros cultivos: Arjmand, et al. [33], en un estudio sobre semillas de cebada tratadas con $\mathrm{ZnSO}_{4}$, junto con fungicidas y polímeros, no observaron diferencias significativas en el potencial de germinación entre las muestras tratadas con diferentes dosis de zinc (ni en el período inicial, ni después de tres y seis meses de almacenaje). De manera similar, Ohse, et al. [5] y Vieira, et al. [22], en trabajos con semillas de arroz recubiertas con zinc, no encontraron diferencias significativas en la germinación. Tampoco Funguetto [34] para semillas de arroz recubiertas con boro, zinc, un fungicida y un polímero, o Trentini, et al. [35] para semillas de soja. Sin embargo, Yagi, et al. [36], en un estudio con sorgo, informaron de una reducción en el porcentaje de germinación, como también lo hicieron Pereira, et al. [37] para semillas de maíz, con una pequeña reducción $(2 \%)$ en el potencial de germinación.

La leve mejoría en términos de germinación de T1 en comparación con el control de T0 estaría de acuerdo con los resultados de Kunkur, et al. [38], que evaluaron el impacto de un fungicida, insecticida y compuesto de polímero en semillas de algodón, observando una mayor germinación después de nueve meses de almacenaje. 


\section{CONGRESO IBÉRICO DE AGROINGENIERÍA \\ X CONGRESSO IBÉRICO DE AGROENGENHARIA \\ 3 - 6 septiembre 2019, Huesca - España}

Tabla 1. Prueba de germinación (GT), antes y después de su almacenaje, de las semillas de algodón recubiertas con una película con diferentes dosis de $\mathrm{ZnSO}_{4}+$ fungicida + insecticida + polímero. Se presentan valores medios. Los coeficientes de variación se mantuvieron por debajo del 3,16\% (antes del almacenaje) y del 3,35\% (después del almacenaje).

\begin{tabular}{ccc}
\hline Tratamiento & GT (\%) antes de almacenaje & GT (\%) después de almacenaje \\
\hline T0 & 88.3 & 86 \\
T1 & 91.0 & 90 \\
T2 & 90.3 & 92 \\
T3 & 90.0 & 89 \\
T4 & 86.0 & 86 \\
T5 & 86.0 & 90 \\
\hline
\end{tabular}

\subsubsection{Primer recuento de germinación}

Esta prueba se basa en el principio de que las muestras que muestran el mayor porcentaje de plántulas normales en el primer recuento son las más vigorosas, evaluando de forma indirecta la tasa de germinación [29]. Por lo tanto, a medida que se reduce la respuesta de las semillas para iniciar el proceso de germinación, es menos probable que expresen su potencial fisiológico para producir plántulas normales y vigorosas y son menos capaces de sobrevivir en condiciones de campo severas.

Antes del almacenaje, los resultados de la primera prueba de recuento (Tabla 2) mostraron que hubo diferencias significativas entre las dosis de T4 y T5 (8,65 y 11,59 g de ZnSO $\cdot \mathrm{kg}^{-1}$ semilla, respectivamente) y T0 (semilla no tratada) y T1 (semilla tratada sólo con $\mathrm{F}+\mathrm{I}+\mathrm{P}$ ), con una reducción notable del vigor de la semilla: T4 llevó a una reducción de $27,5 \%$ en comparación con T0 y a una reducción de 30,85\% en comparación con T1, mientras que T5 dio como resultado un $53,5 \%$ de reducción frente a T0 y en una reducción del 55,7\% frente a T1.

Tabla 2. Primer recuento de germinación (FGC), antes y después del almacenaje, de las semillas de algodón recubiertas con una película con diferentes dosis de $\mathrm{ZnSO}_{4}+$ fungicida + insecticida + polímero. Los valores presentados son valores medios, y los coeficientes de variación se mantuvieron por debajo del 6,66\% (antes de almacenaje) y del 3,94\% (después de almacenaje).

\begin{tabular}{ccc}
\hline Tratamiento & FGC (\%) antes de almacenaje & FGC (\%) después de almacenaje \\
\hline T0 & 79.0 & 86 \\
T1 & 82.8 & 90 \\
T2 & 77.8 & $* 92$ \\
T3 & 76.8 & 89 \\
T4 & $* 57.3 \beta$ & $* 32 \beta$ \\
T5 & $* 36.7 \beta$ & $* 26 \beta$ \\
\hline
\end{tabular}

Los valores medios precedidos por '*' y seguidos por ' $\beta$ ' difieren de los tratamientos T0 y T1, respectivamente, de acuerdo con la prueba de Dunnett $(\mathrm{p} \leq 0,05)$.

Después del almacenaje durante 120 días en condiciones no controladas, los resultados de la prueba de germinación del primer recuento fueron similares a los obtenidos antes del almacenaje, con diferencias significativas para los tratamientos con T4 y T5 en comparación con los controles (T0 y T1). En este caso, T4 redujo el FGC en un $62,8 \%$ y en un $64,4 \%$ en comparación con T0 y T1, respectivamente, mientras que T5 llevó a una reducción del $69,8 \%$ y a una reducción del $71,1 \%$ frente a T0 y T1, respectivamente. Es preciso señalar también que la dosis más baja (T2) condujo a un aumento significativo (7\%) en comparación con T0, pero no frente a T1. 


\section{CONGRESO IBÉRICO DE AGROINGENIERÍA \\ X CONGRESSO IBÉRICO DE AGROENGENHARIA \\ 3 - 6 septiembre 2019, Huesca - España}

\subsection{Patrones de isoenzimas}

A partir de los resultados del análisis de los cuatro sistemas enzimáticos estudiados, fue posible inferir que hubo variaciones significativas en la intensidad de la expresión de isoenzimas, tanto en función de las dosis de zinc aplicadas a las semillas, como antes y después de su almacenaje durante 120 días en condiciones no controladas.

En general, se pudo observar que el patrón de isoenzimas expresado por la semilla seca (0 días) difería de las isoenzimas expresadas por las plántulas en desarrollo para todos los sistemas de proteínas analizados. Esto se puede atribuir al hecho de que los patrones durante el desarrollo de la semilla seca y en la germinación corresponden a diferentes procesos de diferenciación celular y perfiles de expresión génica. En la semilla seca, la actividad metabólica es extremadamente baja y sólo las reacciones biosintéticas necesarias para la respiración celular son sostenidas. Por otro lado, en las plántulas en desarrollo, durante el proceso de germinación, se desencadenan varias reacciones bioquímicas y biosintéticas, como la producción intensa de trifosfato de adenosina (ATP), la degradación de las reservas de proteínas y polisacáridos, la nueva síntesis de ARNm, la reestructuración y reparación de membranas dañadas y orgánulos, etc., que modifican significativamente la expresión de isoenzimas [24].

Antes del almacenaje, las semillas recubiertas con sulfato de zinc mostraron diferencias en la intensidad de las bandas de la enzima carboxilesterasa (ver Figura 1). Al evaluar las plántulas cuatro días después de la emergencia, el control T0 mostró una mayor intensidad de la enzima que el control T1. Para las dosis T3 y T4, se observó una intensidad más baja de la enzima en comparación con las otras muestras tratadas con el micronutriente. Estos resultados difieren de los reportados por Diniz, et al. [39], que encontraron un aumento en la intensidad de las bandas para las semillas de lechuga cubiertas con sales de zinc durante su almacenaje, y por de Tunes, et al. [40], que analizaron las variaciones en la expresión de esta enzima en semillas de cebada durante su almacenaje durante seis meses.
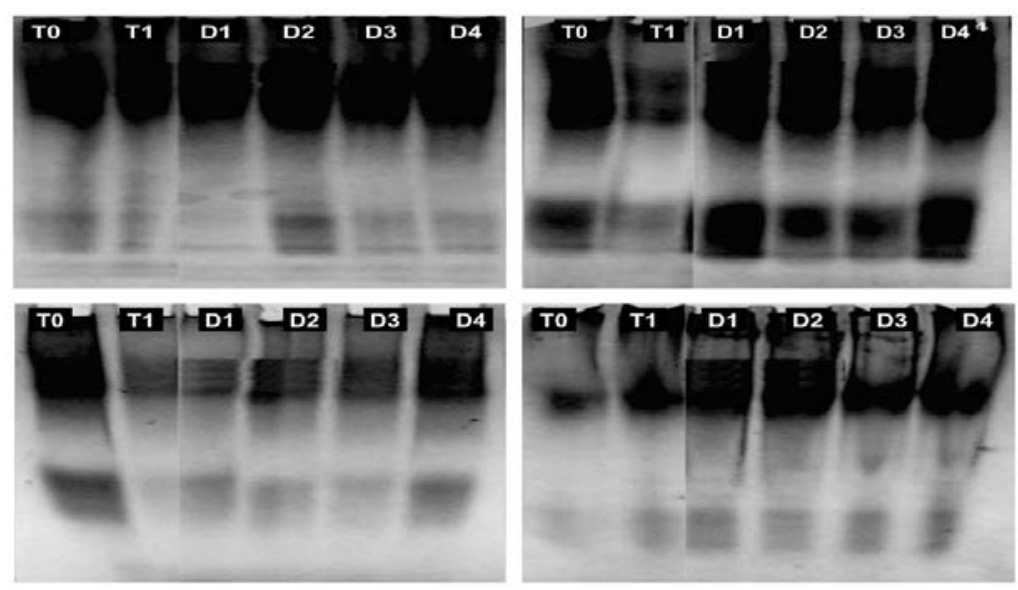

Figura 1. Patrones electroforéticos de la isoenzima carboxilesterasa obtenidos para semillas de algodón (izquierda) y plántulas (derecha) recubiertas con diferentes dosis de $\mathrm{ZnSO}_{4}$ (junto con un fungicida, un insecticida y un polímero), antes (arriba) y después (abajo) de su almacenaje en condiciones no controladas durante 120 días. T0: sin recubrimiento; T1: composite sin $\mathrm{ZnSO}_{4}$; D1: composite con 2,895 $\mathrm{g} \mathrm{ZnSO}_{4} / \mathrm{kg}$ semillas; D2: composite con 5,795 g ZnSO $4 / \mathrm{kg}$ semillas; D3: composite con 8,65 $\mathrm{g} \mathrm{ZnSO}_{4} / \mathrm{kg}$ semillas; D4: composite con 1,585 $\mathrm{g} \mathrm{ZnSO} / / \mathrm{kg}$ semillas.

Cuando se analizaron los resultados de la electroforesis en gel después de 120 días de almacenaje de las semillas en condiciones ambientales no controladas, se evidenció que se produjo una menor expresión de CES para las semillas no tratadas (T0) en comparación con todos los otros tratamientos, con o sin la presencia de sulfato de zinc. En el análisis visual de las bandas 


\section{CONGRESO IBÉRICO DE AGROINGENIERÍA \\ X CONGRESSO IBÉRICO DE AGROENGENHARIA \\ 3 - 6 septiembre 2019, Huesca - España}

en plántulas, se observó una menor expresión de la enzima en los controles T0 y T1 que en las muestras tratadas con el micronutriente.

En semillas de alubia, un aumento en la actividad de CES puede implicar una reducción de la calidad, conforme a lo indicado por Santos, et al. [26], que propusieron que las esterasas pueden usarse como marcadores del proceso de deterioro de las semillas. Lo mismo fue verificado por Silva, et al. [41] en plántulas de maíz tratadas con sales de zinc.

En cuanto a los resultados de electroforesis en gel para la enzima AP (Figura 2), antes y después del almacenaje, no se encontraron diferencias en el número y/o la intensidad de las bandas para ninguno de los tratamientos, ni para las semillas ni para las plantas de semillero.

Como se señaló anteriormente, la fosfatasa ácida es una enzima relacionada con los procesos de deterioro en las semillas, como la interrupción del sistema de membrana celular, causada por la peroxidación de la membrana de fosfolípidos [19-21]. Santos, et al. [26] informaron que, para las semillas de alubia sometidas a envejecimiento artificial, los valores más altos de conductividad eléctrica estaban relacionados con una mayor actividad de la fosfatasa ácida.

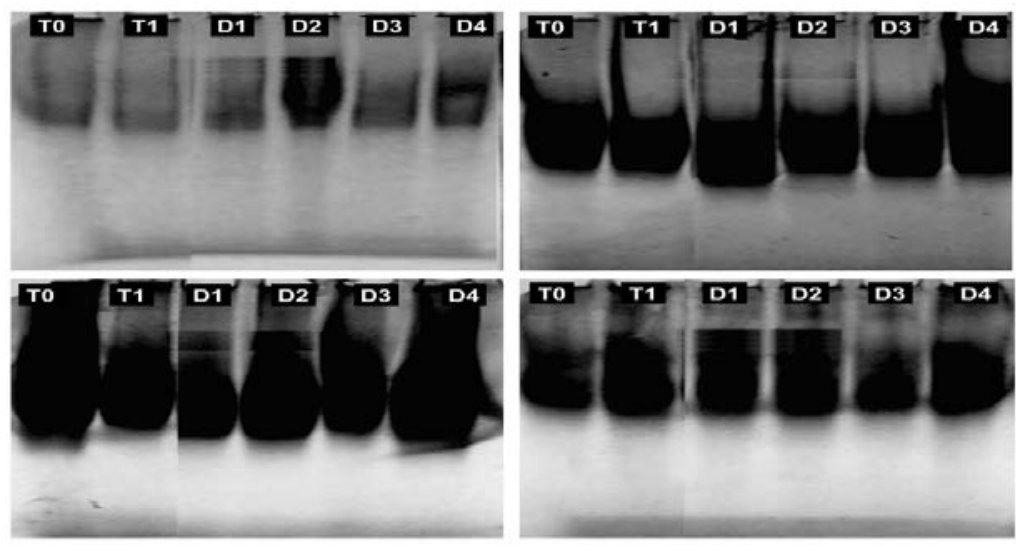

Figura 2. Patrones electroforéticos de fosfatasa ácida obtenidos para semillas de algodón (izquierda) y plántulas (derecha) recubiertas con diferentes dosis de $\mathrm{ZnSO}_{4}$ (junto con un fungicida, un insecticida y un polímero), antes (arriba) y después (abajo) de almacenaje en condiciones no controladas. T0: sin recubrimiento; T1: composite sin $\mathrm{ZnSO}_{4}$; D1: composite con 2,895 g ZnSO $/ \mathrm{kg}$ semillas; D2: composite con 5,795 g ZnSO4/kg semillas; D3: composite con 8,65 g ZnSO $/ \mathrm{kg}$ semillas; D4: composite con 1,585 $\mathrm{g} \mathrm{ZnSO} / \mathrm{kg}$ semillas.

Para el sistema isoenzima de la glutamato-oxalacetato transaminasa (Figura 3), las semillas y las plántulas recubiertas antes del almacenaje no mostraron cambios en el número y la intensidad de las bandas, independientemente de la dosis de zinc utilizada en el tratamiento. Después de 120 días de almacenaje, tampoco se observaron diferencias para las plántulas (4 días después de la emergencia, DAE). No obstante, después de 120 días de almacenaje, se pudo observar una mayor expresión de la GOT para las semillas T1 en comparación con T0. Para T3 y T4, la intensidad de las bandas aumentó con el aumento de la dosis de zinc.

La actividad de la enzima GOT está directamente relacionada con la calidad de la semilla [42], pues participa en el proceso de degradación y síntesis de aminoácidos [42], mostrando un papel importante en la germinación de las semillas. Dado que esta enzima participa directamente en el metabolismo del $\mathrm{N}$, pueden producirse variaciones a medida que la síntesis y la degradación de los aminoácidos tienen lugar durante el proceso de germinación. 

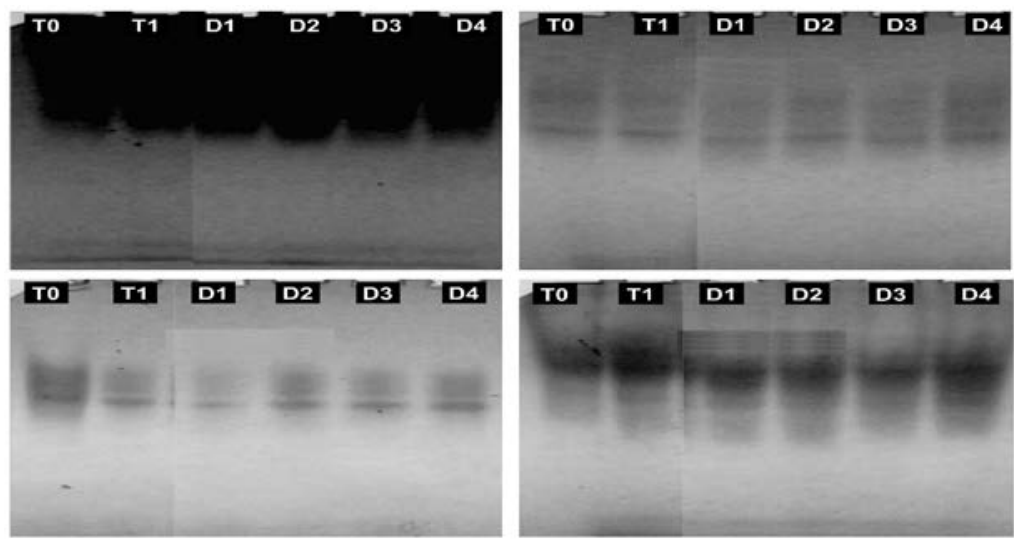

Figura 3. Patrones electroforéticos de glutamato-oxalacetato transaminasa obtenidos para semillas de algodón (izquierda) y plántulas (derecha) recubiertas con diferentes dosis de $\mathrm{ZnSO}_{4}$ (junto con un fungicida, un insecticida y un polímero), antes (arriba) y después (abajo) de almacenaje en condiciones no controladas. T0: sin recubrimiento; T1: composite sin $\mathrm{ZnSO}_{4}$; D1: composite con 2,895 $\mathrm{g} \mathrm{ZnSO}_{4} / \mathrm{kg}$ semillas; D2: composite con 5,795 g ZnSO$/ \mathrm{kg}$ semillas; D3: composite con 8,65 $\mathrm{g} \mathrm{ZnSO} / \mathrm{kg}$ semillas; D4: composite con 1,585 g ZnSO $4 / \mathrm{kg}$ semillas.

La expresión de la enzima glutamato deshidrogenasa (Figura 4) no mostró variaciones en su intensidad de expresión antes del almacenaje de las semillas. Sin embargo, para las plántulas se encontró una expresión más intensa para el control T0 y los tratamientos T3 y T4. Después de 120 días de almacenaje, no se encontraron variaciones en la intensidad y expresión de los patrones de GLDH, ni para las semillas ni para las plántulas 4 DAE, independientemente de la dosis de zinc.

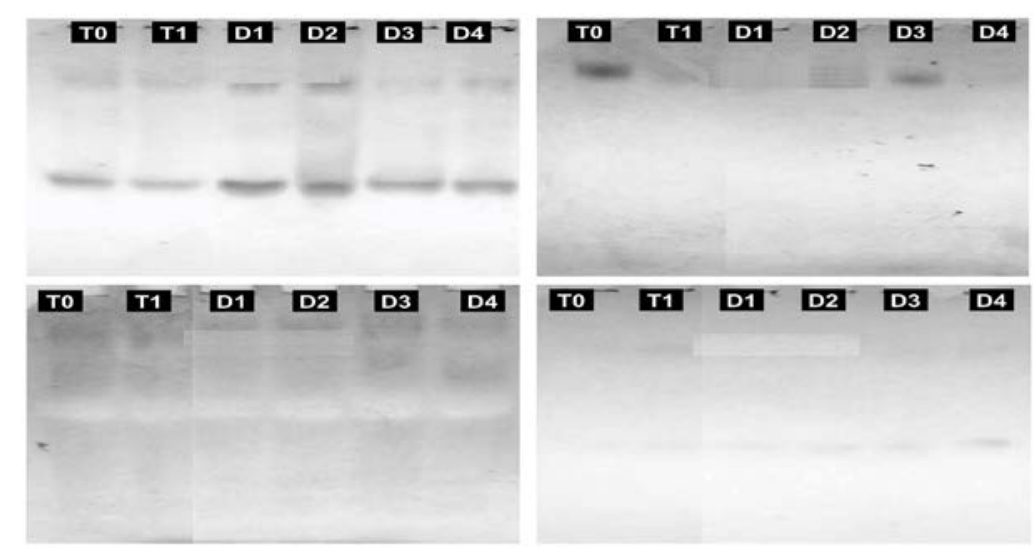

Figura 4. Patrones electroforéticos de glutamato deshidrogenasa obtenidos para semillas de algodón (izquierda) y plántulas (derecha) recubiertas con diferentes dosis de $\mathrm{ZnSO}_{4}$ (junto con un fungicida, un insecticida y un polímero), antes (arriba) y después (abajo) de almacenaje en condiciones no controladas. T0: sin recubrimiento; T1: composite $\sin \mathrm{ZnSO}_{4}$; D1: composite con 2,895 g ZnSO $4 / \mathrm{kg}$ semillas; D2: composite con 5,795 $\mathrm{g} \mathrm{ZnSO}_{4} / \mathrm{kg}$ semillas; D3: composite con 8,65 g $\mathrm{ZnSO}_{4} / \mathrm{kg}$ semillas; D4: composite con 1,585 $\mathrm{g} \mathrm{ZnSO}_{4} / \mathrm{kg}$ semillas.

Esta enzima está, al parecer, gobernada por la expresión de dos loci no vinculados (GLDH 1 y $\mathrm{GLDH}_{2}$ ) [43-45]. Esta enzima actúa sobre la oxidación de aminoácidos (proteínas de almacenaje), proporciona energía para las células (ciclo de Krebs) y/o la reducción de $\alpha$ cetoglutarato para la síntesis de aminoácidos, y probablemente desempeña un papel importante en la germinación de las semillas, proporcionando energía al proceso. o aminoácidos para el desarrollo embrionario. Según Brandão-Junior, et al. [23], esta enzima tiene una alta correlación entre la actividad disminuida y la calidad reducida de la semilla. 


\section{CONGRESO IBÉRICO DE AGROINGENIERÍA \\ X CONGRESSO IBÉRICO DE AGROENGENHARIA \\ 3 - 6 septiembre 2019, Huesca - España}

\section{Conclusiones}

El recubrimiento de las semillas de algodón con composites a dosis de 2,9 g ZnSO $/ \mathrm{kg}$ de semillas y $5,8 \mathrm{~g} \mathrm{ZnSO}_{4} / \mathrm{kg}$ de semillas han dado lugar a las mejores tasas de germinación y al mayor vigor de las plántulas tras su almacenaje durante un cuatrimestre (aunque sin diferencias significativas desde un punto de vista estadístico). Otro es el caso cuando se aumenta la dosis de $\mathrm{ZnSO}_{4}$ pues tras 120 días de almacenaje se observa una indeseada reducción del vigor. Respecto a las cuatro isoenzimas cuya actividad se ha medido para evaluar la calidad de las semillas (carboxilesterasa, fosfatasa ácida, glutamato-oxalacetato transaminasa y glutamato deshidrogenasa), se han registrado diferencias en dos enzimas tras los 4 meses de almacenaje. Los valores más bajos de carboxilesterasa (cuyo aumento va asociado al metabolismo de lípidos y a degeneración de la membrana) y los más altos de glutamato-oxalacetato transaminasa (clave en el metabolismo de las proteínas) se han obtenido para las semillas tratadas con $\mathrm{ZnSO}_{4}$ a $5,8 \mathrm{~g} / \mathrm{kg}$ de semillas, que se plantea como la dosis más deseable en los ensayos realizados con el cultivar BRS 286. La aplicación de sulfato de zinc con una adecuada dosificación, en forma de composite, se plantea pues como una vía de mejora de la viabilidad de las semillas de algodón durante su almacenaje.

\section{Referencias}

1. USDA. Circular Series on World Agricultural Production 5-19; United States Department of Agriculture Foreign Agricultural Service: USA, 2019; p 31.

2. Vale, F. Avaliação e caracterização da disponibilidade do boro e zinco contidos em fertilizantes. Universidade de São Paulo, Piracicaba, Brazil, 2001.

3. Volkweiss, S.J.; Tedesco, M.J.; Bohnen, H. Levantamento dos teores de nutrientes das plantas em solos do Rio Grande do Sul. UFRGS: Porto Alegre, Brazil, 1983; p 60.

4. Ohse, S.; dos Santos, O.S.; Morodim, V.; Manfron, P.A. Efeito do tratamento de sementes de arroz irrigado com zinco em relação a aplicação no substrato. Revista da FZVA 1998, 5.

5. $\quad$ Ohse, S.; Marodim, V.; Dos Santos, O.S.; Lopes, S.J.; Manfron, P.A. Germinação e vigor de sementes de arroz irrigado tratadas com zinco, boro e cobre. Revista da FZVA 2001, 7/8, 41-50.

6. Fageria, N.K. Níveis adequados e tóxicos de zinco na produção de arroz, feijão, milho, soja e trigo em solo de cerrado. Revista Brasileira de Engenharia Agrícola e Ambiental 2000, 4, 390-395.

7. Fageria, N.K. Screening method of lowland rice genotypes for zinc uptake efficiency. Scientia Agricola 2001, $58,623-626$.

8. Fageria, N.K. Influence of micronutrients on dry matter yield and interaction with other nutrients in annual crops. Pesquisa Agropecuária Brasileira 2002, 37, 1765-1772.

9. Marchezan, E.; Santos dos Santos, O.; Avila, L.A.d.; Posser da Silva, R. Adubação foliar com micronutrientes em arroz irrigado, em área sistematizada. Ciência Rural 2001, 31, 941-945.

10. de Oliveira, S.C.; Costa, M.C.G.; Chagas, R.d.C.S.; Fenilli, T.A.B.; Heinrichs, R.; Cabral, C.P.; Malavolta, E. Resposta de duas cultivares de arroz a doses de zinco aplicado como oxissulfato. Pesq. agropec. bras., Brasília 2003, 38, 387-396.

11. Bonnecarrère, R.A.; Londero, F.A.; Santos, O.; Schmidt, D.; Pilau, F.G.; Manfron, P.A.; Neto, D.D. Resposta de genótipos de arroz irrigado à aplicação de zinco. Revista da FZVA 2003, 10, 109-116.

12. Moraes, M.F.d.; Santos, M.G.d.; Bermúdez-Zambrano, O.D.; Malavolta, M.; Raposo, R.W.C.; Cabral, C.P.; Malavolta, E. Resposta do arroz em casa de vegetação a fontes de micronutrientes de diferentes granulometria e solubilidade. Pesquisa Agropecuária Brasileira 2004, 39, 611-614.

13. Fageria, N.K.; Baligar, V.C. Growth components and zinc recovery efficiency of upland rice genotypes. Pesquisa Agropecuária Brasileira 2005, 40, 1211-1215.

14. Baudet, L.; Peske, F. Aumentando o desempenho das sementes. Seed News 2007, 9, 22-24.

15. Levien, A.; Peske, S.T.; Baudet, L. Film coating no recobrimento das sementes. Seed News 2008, 12, 1-5.

16. Baudet, L.; Villela, F.A. Armazenamento de sementes. In Sementes: fundamentos científicos e Tecnológicos, $2^{\text {nd }}$ ed.; Peske, S.T.; Lucca Filho, O.A.; Barros, A.C.S.A., Eds. UFPel: Pelotas, Brazil, 2006; pp 427-472. 


\section{CONGRESO IBÉRICO DE AGROINGENIERÍA \\ X CONGRESSO IBÉRICO DE AGROENGENHARIA \\ 3 - 6 septiembre 2019, Huesca - España}

17. Ramírez, H.; Calderón, A.; Roca, W.M. Técnicas moleculares para evaluar y mejorar el germoplasma vegetal. In Cultivo de Tejidos Vegetales en la Agricultura. Fundamentos y Aplicaciones, Roca, W.M.; Mroginski, L.A., Eds. Centro Internacional de Agricultura Tropical (CIAT): Cali, Colombia, 1991; pp 825-855.

18. Tunes, L.M. Atributos de qualidade em sementes de trigo recobertas com zinco durante e após o armazenamento. Universidade Federal de Santa Maria, Santa Maria, Brasil, 2011.

19. Spinola, M.C.M.; Cícero, S.M.; Melo, M. Alterações bioquímicas e fisiológicas em sementes de milho causadas pelo envelhecimento acelerado. Scientia Agricola 2000, 57, 263-270.

20. Carvalho, M.; Vieira, M.; Pinho, E. Técnicas moleculares em sementes. Biotecnologia, Ciência E Desenvolvimento, Brasília 2000, 3, 44-47.

21. Santos, C.M.R.; Menezes, N.d.; Villela, F.A. Modificações fisiológicas e bioquímicas em sementes de feijão no armazenamento. Revista Brasileira de Sementes 2005, 27, 104-114.

22. Vieira, E.H.N.; Moreira, G.A. Peletização de sementes de arroz. In Comunicado Técnico, Embrapa Arroz e Feijão: Santo Antônio de Goiás, Brazil, 2005; Vol. 111, p 2.

23. Brandão-Junior, D.d.S.; Carvalho, M.L.M.d.; Vieira, M.G.G.C. Variações eletroforéticas de proteínas e isoenzimas relativas à deterioração de sementes de milho envelhecidas artificialmente. Revista Brasileira de Sementes 1999, 21, 114-121.

24. Malone, G. Relações bioquímicas e moleculares da germinação e emergência em arroz. Universidade Federal de Pelotas, Pelotas, Brazil, 2007.

25. Vieira, M.d.G.G.C. Utilização de marcadores moleculares no monitoramento da qualidade sanitária e nível de deterioração de sementes de algodoeiro (Gossypium hirsutum L.). Universidade Federal de Lavras, Lavras, Minas Gerais, Brazil, 1996.

26. Santos, C.M.R.; Menezes, N.L.d.; Villela, F.A. Alterações fisiológicas e bioquímicas em sementes de feijão envelhecidas artificialmente. Revista Brasileira de Sementes 2004, 26, 110-119.

27. Chauhan, K.; Gopinathan, M.; Babu, C. Electrophoretic variations of proteins and enzymes in relation to seed quality. Seed Science and Technology 1985, 13, 629-641.

28. Nunes, J.C. Tratamento de semente-qualidade e fatores que podem afetar a sua performance em laboratório. Londrina: Syngenta Proteção de Cultivos Ltda 2005.

29. Brasil Mapa/ACS. Regras para análise de sementes. Brasil - Ministério da Agricultura, Pecuária e Abastecimento. Secretaria de Defesa Agropecuária: Brasília, Brasil, 2009; p 399.

30. Scandalios, J.G. Genetic control of multiple molecular forms of enzymes in plants: a review. Biochem. Genet. 1969, 3, 37-79.

31. de Souza Lima, M.d.G.; Lopes, N.F.; Zimmer, P.D.; Meneghello, G.E.; Mendes, C.R.; do Amarante, L. Enzyme expression in indica and japonica rice cultivars under saline stress. Acta Scientiarum. Biological Sciences 2012, 34, 473-481.

32. Alfenas, A.C. Eletroforese de isoenzimas e proteínas afins: fundamentos e applicações em plantas e microrganismos. Universidade Federal de Viçosa: Viçosa, Brazil, 1998; p 574.

33. Arjmand, H.S.; Abarghooei, G.H.B.; Ghorbanpour, M.; Sharafi, S. Effect of zinc coated during storage on the seed quality of barley. International Journal of Farming and Allied Science 2014, 3, 845-850.

34. Funguetto, C.I. Recobrimento de sementes de arroz irrigado com zinco e polímero. Norte Científico 2011, 2, 80-92.

35. Trentini, P.; Vieira, M.d.G.G.C.; Carvalho, M.L.M.d.; Oliveira, J.A.d.; Machado, J.d.C. Peliculização: desempenho de sementes de soja no estabelecimento da cultura em campo na região de alto garças, MT. Ciência e Agrotecnologia 2005, 29.

36. Yagi, R.; Simili, F.F.; Araújo, J.C.d.; Prado, R.d.M.; Sanchez, S.V.; Ribeiro, C.E.R.; Barretto, V.C.d.M. Aplicação de zinco via sementes e seu efeito na germinação, nutrição e desenvolvimento inicial do sorgo. Pesquisa Agropecuária Brasileira 2006, 41, 655-660.

37. Pereira, C.; Oliveira, J.A.; Evangelista, J.R.E. Qualidade fisiológica de sementes de milho tratadas associadas a polímeros durante o armazenamento. Ciência e Agrotecnologia 2005, 29, 1201-1208.

38. Kunkur, V.; Hunje, R.; BiradarPatil, N.; Vyakarnahal, B. Effect of seed coating with polymer, fungicide and insecticide on seed quality in cotton during storage. Karnataka Journal of Agricultural Sciences 2010, 20. 


\section{CONGRESO IBÉRICO DE AGROINGENIERÍA \\ X CONGRESSO IBÉRICO DE AGROENGENHARIA \\ 3 - 6 septiembre 2019, Huesca - España}

39. Diniz, K.A.; Oliveira, J.A.; Silva, P.d.A.; Guimarães, R.M.; Carvalho, M.L.M.d. Qualidade de sementes de alface enriquecidas com micronutrientes e reguladores de crescimento durante o armazenamento. Revista Brasileira de Sementes 2009, 31.

40. de Tunes, L.M.; Badinelli, P.G.; Barros, A.C.S.A.; Meneghello, G.E.; do Amarante, L. Influência dos diferentes períodos de colheita na expressão de isoenzimas em sementes de cevada. Revista Ceres 2011, 58, 178-184.

41. Silva, T.T.d.A.; Von Pinho, É.V.d.R.; Cardoso, D.L.; Ferreira, C.A.; Alvim, P.d.O.; Costa, A.A.F.d. Qualidade fisiológica de sementes de milho na presença de bioestimulantes. Ciênc. agrotec.,(Impr.) 2008, 32, 840-844.

42. Costa, C.J.; Villela, F.A.; Bertoncello, M.R.; Tillmann, M.Â.A.; Menezes, N.L.d. Expressão de isoenzimas após a pré-hidratação de sementes de ervilha. Revista Brasileira de Sementes 2008, 30, 130-138.

43. Misharin, S.; Mozgova, E.; Monastyreva, L.; Sukhorzhevskaia, T.; Khavkin, E. Protein polymorphism in maize and its nearest relatives. Maize Genetic Cooperation News Letter 1979, 53, 44-46.

44. Sukhorzhevskaya, T.B. Organ-specific spectra of glutamate dehydrogenase in maize Zea mays L. Soviet Journal of Developmental Biology (USA) 1979.

45. Sukhorzhevskaya, T.B. Investigation of genetic control over glutamate dehydrogenase in maize (Zea mays L.). Genetika 1980, 16, 914-917. 